Check for updates

Cite this: RSC Adv., 2021, 11, 32852

\title{
Revisiting the covalent nature of halogen bonding: a polarized three-center four-electron bond $\dagger$
}

\begin{abstract}
Dan Li, ${ }^{a}$ Tao Xia, ${ }^{a}$ Wanwan Feng ${ }^{a}$ and Longjiu Cheng $\mathbb{D}$ *ab
As an important intermolecular interaction, halogen bonding has been studied extensively, but its nature still suffers from controversy without one uniform essence. Electrostatics, charge transfer, polarization and dispersion are emphasized, but the covalent nature is usually overlooked except for the strong halogen bonding species $\mathrm{I}_{3}^{-}$, which is widely accepted as a result of a three-center four-electron $(3 \mathrm{c}-4 \mathrm{e}$ ) interaction. In our study, the potential energy surface of $\mathrm{I}_{3}^{-}$has been evaluated to explore the dissociation from $\mathrm{I}_{3}^{-}$to $\left.\mathrm{I}_{2} \cdots\right|^{-}$. We found that different from an equivalent $3 \mathrm{c}-4 \mathrm{e}$ bond in $\mathrm{I}_{3}^{-},\left.\mathrm{I}_{2} \cdots\right|^{-}$can be rationalized by a polarized one. In addition, when the orbitals are polarized, it is exactly what traditional charge transfer or the popular $\sigma$-hole picture describes. $\mathrm{I}_{3}{ }^{-}$can be described by the Lewis theory model with the middle $\mathrm{I}^{+}$cation serving as the Lewis acid and two terminal $\mathrm{I}^{-}$anions acting as Lewis base. Therefore, we further extended this model to a series of I-containing species with chemical

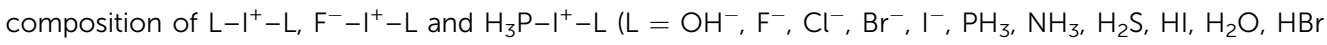
and $\mathrm{HCl}$ ) to explore the nature of halogen bonding. When the forces of two bases around $\mathrm{I}^{+}$are the same, it corresponds to an equivalent $3 \mathrm{c}-4 \mathrm{e}$ bond, such as $\mathrm{I}_{3}{ }^{-}$. Otherwise, it is a polarized multicenter bond, such as $\left.I_{2} \cdots\right|^{-}$. This work gives a new insight into the nature of halogen bonding compounds: besides the well-known $\mathrm{I}_{3}^{-}$, the nature of the other species is also a multicenter bond, existing as equivalent and polarized $3 c-4 e$ bonds, respectively.
\end{abstract}

Received 11th August 2021

Accepted 20th September 2021

DOI: 10.1039/d1ra05695f

rsc.li/rsc-advances
Halogen bonding has a general form of $\mathrm{Y}-\mathrm{X} \cdots \mathrm{D}^{5,32}$ (Scheme 1), where $\mathrm{X}$ is a halogen atom, and it functions as the electrophilic species (halogen bond donor), and D is a donor of electron density (halogen bond acceptor). The distance of $\mathrm{X} \cdots \mathrm{D}$ is shorter than the sum of their van der Waals radii, and the YX bond length is slightly elongated than the YX monomer, and the $\mathrm{Y}-\mathrm{X} \cdots \mathrm{D}$ angle is approximately linear. ${ }^{2-4}$

Though studied extensively, the exact nature of halogen bonding is still disputed. Classically, the chemical nature of the interaction was explained as charge transfer by Mulliken in $1950 .^{33}$ More precisely, in a charge transfer picture, halogen bonding is described as a donation from the donor lone pair into the $\sigma^{*}$ antibonding orbital. ${ }^{34-40}$ Some computational studies have found a good correlation between the degree of charge transfer and the halogen bonding strength. ${ }^{\mathbf{4 0 , 4 1}}$ Besides, a more widespread model of this kind of interaction is based on bonding has led to a range of applications in the biological field, ${ }^{3,29}$ such as drug $\operatorname{design}^{30}$ and protein-ligand complexation. ${ }^{31}$

${ }^{a}$ Department of Chemistry, Anhui University, Hefei, 230601, PR China. E-mail: clj@ ustc.edu

${ }^{b}$ Key Laboratory of Structure and Functional Regulation of Hybrid Materials (Anhui University), Ministry of Education, Hefei, 230601, PR China

$\dagger$ Electronic supplementary information (ESI) available. See DOI: 10.1039/d1ra05695f

\section{the electrostatic effect. The electron density in a halogen atom is}

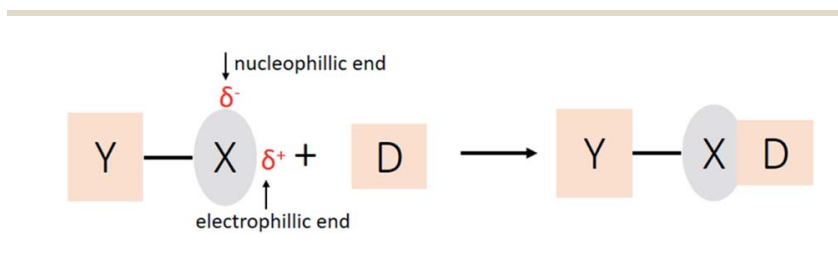

Scheme 1 General scheme for the formation of a halogen bond. 

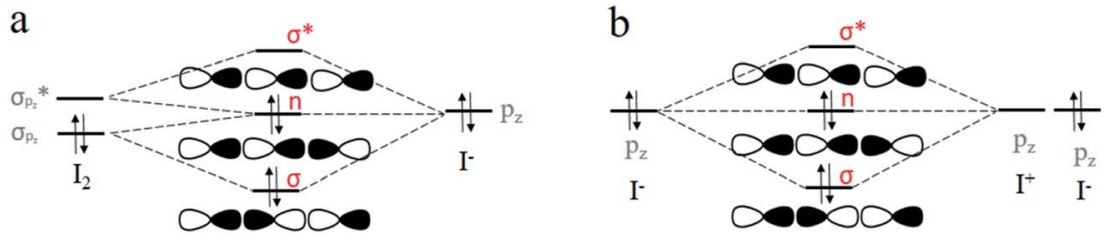

Fig. 1 Molecular orbitals scheme for the formation of $\mathrm{I}_{3}^{-}$by $(\mathrm{a})\left(\mathrm{I}_{2}+\mathrm{I}^{-}\right)$model, where $\mathrm{I}_{3}^{-}$results from the overlap of orbitals of $\mathrm{I}_{2}$ and $\mathrm{I}^{-}$, and (b) $\left(\mathrm{I}^{+}\right.$ $+2 \mathrm{I}^{-}$) model, where $\mathrm{I}_{3}^{-}$results from the overlap of orbitals of two $\mathrm{I}^{-}$and one $\mathrm{I}^{+}$.

Table 1 Benchmark on the bond length, frequency of the $|-|$ bond and binding energy of molecular $\mathrm{I}_{2}$

\begin{tabular}{llll}
\hline Theoretical level & $\mathrm{R}_{\mathrm{I}-\mathrm{I}}(\AA)$ & Freq $_{\mathrm{I}-\mathrm{I}}\left(\mathrm{cm}^{-1}\right)$ & $E_{\mathrm{b}}{ }^{a}\left(\mathrm{kcal} \mathrm{mol}^{-1}\right)$ \\
\hline Experiment & & & \\
CCSD(T)/dhf-QZVP & 2.666 & 215.5 & -35.9 \\
B3LYP-D3(BJ)/dhf-QZVP & 2.659 & 224.4 & -44.9 \\
B3LYP-D3(BJ)/def2-TZVPP & 2.688 & 213.5 & -46.3 \\
M06-2X/dhf-QZVP & 2.651 & 233.3 & -46.5 \\
M06-2X/def2-TZVPP & $\mathbf{2 . 6 5 2}$ & $\mathbf{2 3 2 . 5}$ & -33.7 \\
\end{tabular}

${ }^{a}$ Binding energy of $\mathrm{I}_{2}$ is defined based on the calculation of $E_{\mathrm{b}}=E\left(\mathrm{I}_{2}\right)-$ $2 E(\mathrm{I})$, where $E\left(\mathrm{I}_{2}\right)$ or $E(\mathrm{I})$ suggests the corresponding single point energies. ${ }^{b}$ Refer to the ref. 64 .

anisotropically distributed when the atom is covalently bonded to other atoms, resulting in regions with positive potential at the terminus of the YX bond $\left(\delta^{+}\right.$in Scheme 1$)$, which is introduced as a " $\sigma$-hole" in 2007 based on computational studies. ${ }^{42,43}$ The $\sigma$-hole perspective states that halogen bonding is an electrostatic attraction between the $\sigma$-hole and the negative potential of a Lewis base. ${ }^{2-4}$ This concept is frequently used, but pure electrostatic interactions have been questioned. ${ }^{\mathbf{4 4 , 4 5}}$ Huber et al. have found that in case of $\mathrm{CX}_{3} \mathrm{I}(\mathrm{X}=\mathrm{F}, \mathrm{Cl}, \mathrm{Br}$ and $\mathrm{I})$, the $\sigma$-hole trend is exactly opposite to the trend in binding energy. ${ }^{46}$ Furthermore, polarization and dispersion contributions cannot be overlooked. ${ }^{2,3,47,48}$ Energy decomposition analysis is widely used by theoretical methods to analyze the components of different interactions. ${ }^{32,41,49}$ Overall, the nature depends upon the individual interacting species, ${ }^{3}$ and no model can explain all observed features.

Halogen bonding is comparable in interaction energy (from 5 to $200 \mathrm{~kJ} \mathrm{~mol}^{-1}$ ) to the well-known hydrogen bonding, ${ }^{50-54}$ and $\mathrm{I}_{3}{ }^{-}$is the strongest. ${ }^{4,5,55}$ It is widely accepted that $\mathrm{I}_{3}{ }^{-}$can be considered as the result of a three-center four-electron (3c-4e) interaction. ${ }^{56-61}$ The $3 \mathrm{c}-4 \mathrm{e}$ bonding pattern for $\mathrm{I}_{3}{ }^{-}$can be rationalized by an MO picture in Fig. 1a. Three MOs are bonding $(\sigma)$, non-bonding (n) and antibonding $\left(\sigma^{*}\right)$ orbitals formed primarily by $\sigma_{\mathrm{pz}}$ and $\sigma_{\mathrm{pz}}^{*}$ orbitals of $\mathrm{I}_{2}$ and $\mathrm{p}_{\mathrm{z}}$ orbital of $\mathrm{I}^{-} . \mathrm{I}^{-}$lone pair contributes two electrons, and I-I bonding pair contributes another two, for a total of 4e. These two pairs of electrons occupy $\sigma$ and $n$ orbitals, leaving the $\sigma^{*}$ orbital vacant. A similar case is the short strong hydrogen bond, represented by $[\mathrm{F}-\mathrm{H}-$ $\mathrm{F}]^{-}$, which can also be considered as an equivalent multicenter interaction, and was recently verified experimentally by Tokmakoff et al. $^{62}$

In our opinion, as shown in Fig. $1 \mathrm{~b}, \mathrm{I}_{3}{ }^{-}$can be described by the Lewis theory model with the middle $\mathrm{I}^{+}$cation serving as the Lewis acid and two terminal $\mathrm{I}^{-}$anions acting as the Lewis base, each ion providing one $\mathrm{p}_{\mathrm{z}}$ orbital to form bonding $(\sigma)$, nonbonding (n) and antibonding $\left(\sigma^{*}\right)$ orbitals. Similarly, 4e occupy $\sigma$ and $\mathrm{n}$ orbitals. We speculate that its nature of an equivalent $3 \mathrm{c}-4 \mathrm{e}$ bond is ascribed to the same forces coming from two terminal $\mathrm{I}^{-}$. Inspired by this, in this study, we
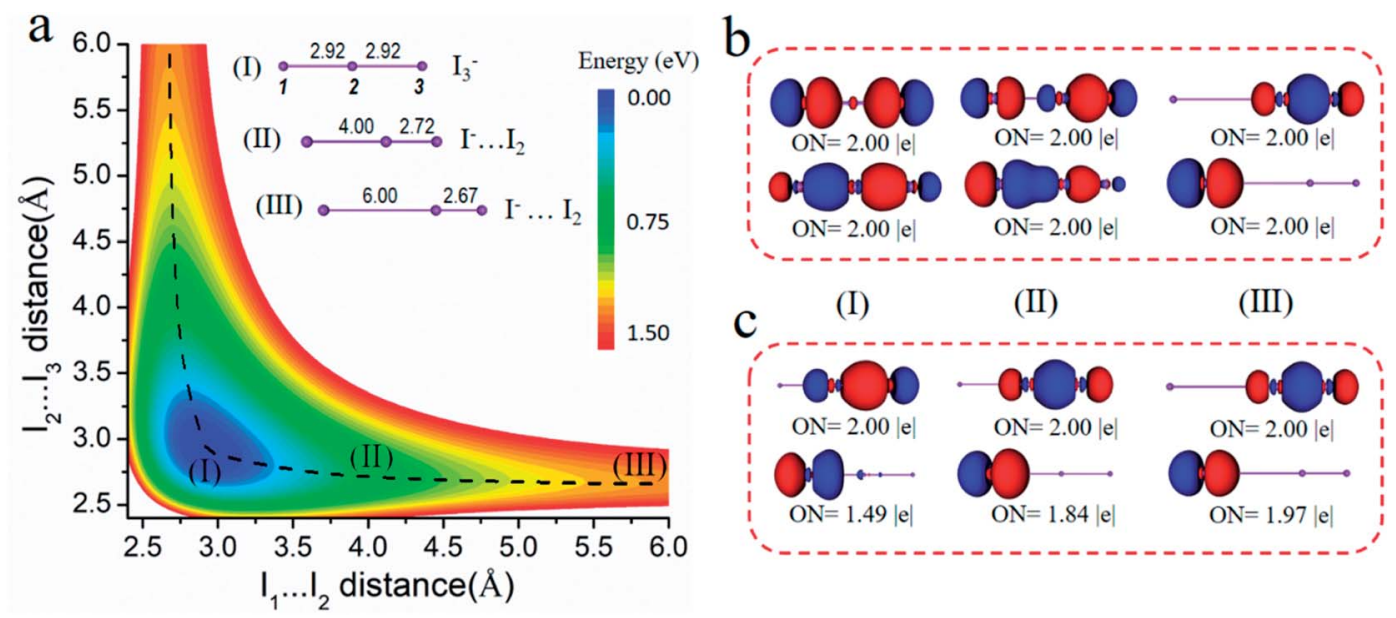

Fig. 2 (a) Potential energy surface of $\mathrm{I}_{3}{ }^{-}$, bonding and non-bonding orbitals of structures I, II and III (as labeled) by the AdNDP analysis based on (b) the $3 \mathrm{c}-4 \mathrm{e}$ model and $(\mathrm{c})$ traditional model $\left(\mathrm{I}_{2}+\mathrm{I}^{-}\right)$. 


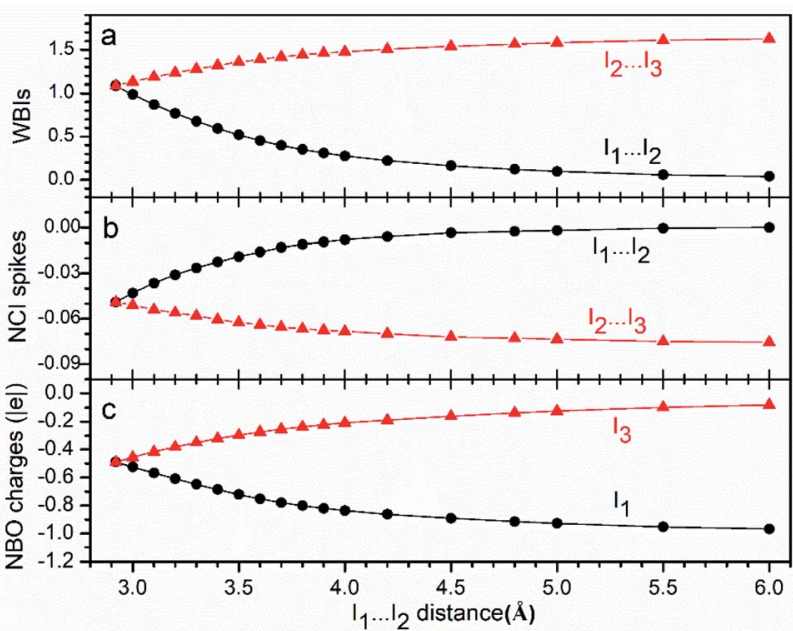

Fig. 3 Values of WBIs (a), NCl spikes (b) and NBO charges (c) during the dissociation of $\mathrm{I}_{3}^{-}$

performed theoretical studies on species composed of $\mathrm{I}^{+}$and two bases $\left(\mathrm{L}-\mathrm{I}^{+}-\mathrm{L}, \mathrm{F}^{-}-\mathrm{I}^{+}-\mathrm{L}\right.$ and $\mathrm{H}_{3} \mathrm{P}-\mathrm{I}^{+}-\mathrm{L}$, where $\mathrm{L}=\mathrm{OH}^{-}, \mathrm{F}^{-}$, $\mathrm{Cl}^{-}, \mathrm{Br}^{-}, \mathrm{I}^{-}, \mathrm{PH}_{3}, \mathrm{NH}_{3}, \mathrm{H}_{2} \mathrm{~S}, \mathrm{HI}, \mathrm{H}_{2} \mathrm{O}, \mathrm{HBr}$ and $\mathrm{HCl}$ ) to explore the nature of the halogen bonding. We found that besides $\mathrm{I}_{3}{ }^{-}$, other halogen bond compounds can also be well explained by multicenter bonds by analyzing their structural and electronic properties. Thus, we propose a new perspective on halogen bonding: its nature should be a multicenter bond, corresponding to equivalent and polarized $3 \mathrm{c}-4 \mathrm{e}$ bonds, respectively.

\section{Computational methods}

To confirm the computational method for our system, we performed calculations under several density functional theory (DFT) and the CCSD(T) theoretical levels to compare the values of the bond length, frequency and interaction energy with the corresponding experimental results for $\mathrm{I}_{2}$. As depicted in Table 1, the I-I bond length at the M06-2X ${ }^{63} /$ def2tzvpp level (2.652 $\AA$ ) was close to that at the CCSD(T)/dhf-QZVP level (2.659 $\AA)$, and they were slightly shorter than the experimental value $(2.666 \AA) .{ }^{64}$ Compared with other methods, M06-2X/def2-TZVPP was considered to be appropriate, and our calculations on halogen bonding in this study were all given at the M06-2X/ def2tzvpp level.

All the geometric structures were fully relaxed at the M06-2X/ def2tzvpp level of theory. Frequencies of all the halogen bonding compounds were all checked to ensure that they were true local minimums. All bonding energies were calculated including basis set superposition error (BSSE) corrections $\mathrm{s}^{65}$ and were referenced to the optimized geometries of the fragments that compose the molecule.

Noncovalent interactions (NCI) ${ }^{66}$ indexes, which is an approach to detect the strength of the weak interactions based on the electron density and its derivatives was selected. The results are shown in the scatter plots of the reduced density gradient (RDG) versus the electron density $(\rho)$ multiplied by the sign of $\lambda_{2}\left(\operatorname{sign}\left(\lambda_{2}\right) \rho\right)$. The low-density regime represents noncovalent/weak interactions. Negative values $\left(\operatorname{sign}\left(\lambda_{2}\right) \rho<0\right)$ indicate an attractive interaction, while positive values $\left(\operatorname{sign}\left(\lambda_{2}\right)\right.$ $\rho>0)$ are indicative of a steric repulsion. Spike mentioned in this study corresponds to the value of $\operatorname{sign}\left(\lambda_{2}\right) \rho$ of interaction. In general, more negative values of NCI spikes indicate a stronger interaction between the fragments.

Chemical bonding analysis was carried out using the adaptive natural density partitioning (AdNDP) ${ }^{67}$ method. It is a tool that provides the partitioning of electron density. It allows an electron pair to be delocalized over $\mathrm{n}$ atoms with $\mathrm{n}$ ranging from one to the total number of atoms in the whole molecule. This method accepts only those bonding elements whose occupation numbers (ON) exceed the specified threshold values, which are usually chosen to be close to $2.00|e|$.

All DFT calculations and natural bond orbital $(\mathrm{NBO})^{68,69}$ analysis were performed on the Gaussian 16 package. ${ }^{70}$ Wiberg bond index (WBI) ${ }^{71}$ and NCI analysis were performed by the Multiwfn 3.4 program. ${ }^{72}$ Molecular visualization was performed using the MOLEKEL 5.4 software. $^{73}$
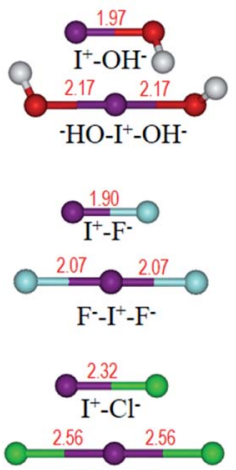

$\mathrm{Cl}^{-}-\mathrm{I}^{+}-\mathrm{Cl}^{-}$

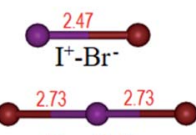

$\mathrm{Br}^{-}-\mathrm{I}^{+}-\mathrm{Br}$
$-\mathrm{HO}^{+} \mathrm{I}^{+}-\mathrm{OH}^{-}$
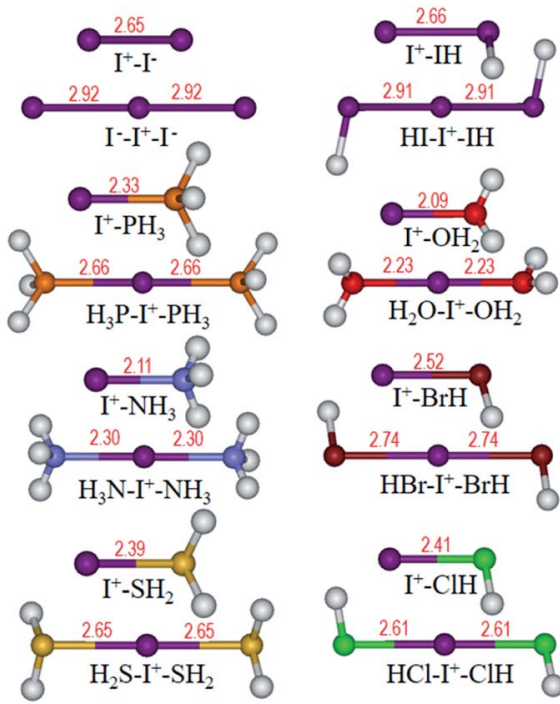

Fig. 4 Optimized structures of $\mathrm{L}-\mathrm{I}^{+}$and $\mathrm{L}-\mathrm{I}^{+}-\mathrm{L}\left(\mathrm{L}=\mathrm{OH}^{-}, \mathrm{F}^{-}, \mathrm{Cl}^{-}, \mathrm{Br}^{-}\right.$, $\mathrm{I}^{-}, \mathrm{PH}_{3}, \mathrm{NH}_{3}, \mathrm{H}_{2} \mathrm{~S}, \mathrm{HI}, \mathrm{H}_{2} \mathrm{O}, \mathrm{HBr}$ and $\mathrm{HCl}$ ) complexes. Bond length $(\AA)$ is labelled in red.

Table 2 Binding energy of $\mathrm{I}^{+}$with various bases

\begin{tabular}{|c|c|c|c|c|c|c|}
\hline Bases & $\mathrm{OH}^{-}$ & $\mathrm{F}^{-}$ & $\mathrm{Cl}^{-}$ & $\mathrm{Br}^{-}$ & $\mathrm{I}^{-}$ & $\mathrm{PH}_{3}$ \\
\hline$E_{\mathrm{b}}\left(\mathrm{kcal} \mathrm{mol}^{-1}\right)$ & -252.40 & -227.47 & -206.16 & -201.61 & -201.29 & -89.88 \\
\hline Bases & $\mathrm{NH}_{3}$ & $\mathrm{H}_{2} \mathrm{~S}$ & $\mathrm{HI}$ & $\mathrm{H}_{2} \mathrm{O}$ & $\mathrm{HBr}$ & $\mathrm{HCl}$ \\
\hline$E_{\mathrm{b}}\left(\mathrm{kcal} \mathrm{mol}^{-1}\right)$ & -64.66 & -52.12 & -40.10 & -29.15 & -25.74 & -16.25 \\
\hline
\end{tabular}




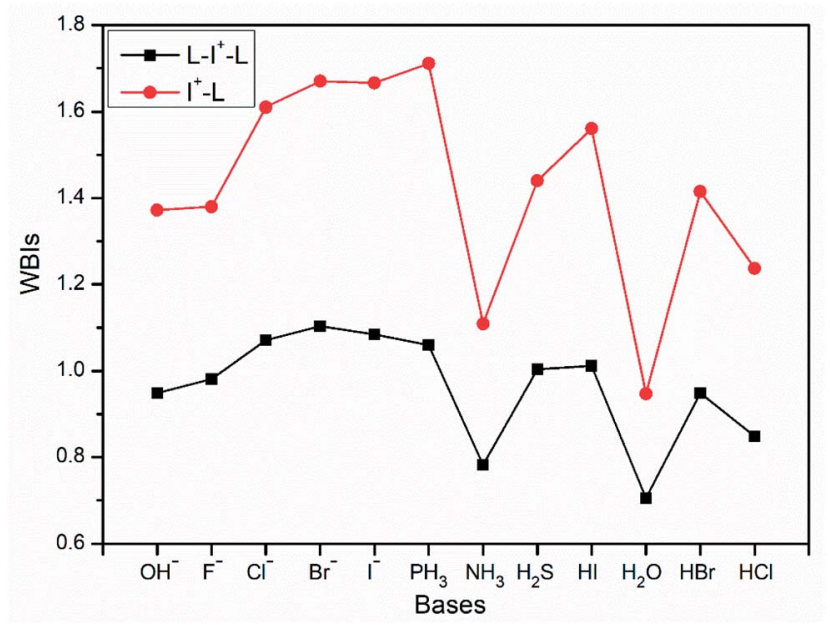

Fig. 5 Values of WBls of $\mathrm{L}-\mathrm{I}^{+}-\mathrm{L}$ and $\mathrm{I}^{+}-\mathrm{L}$ complexes with different bases $\left(\mathrm{OH}^{-}, \mathrm{F}^{-}, \mathrm{Cl}^{-}, \mathrm{Br}^{-}, \mathrm{I}^{-}, \mathrm{PH}_{3}, \mathrm{NH}_{3}, \mathrm{H}_{2} \mathrm{~S}, \mathrm{HI}, \mathrm{H}_{2} \mathrm{O}, \mathrm{HBr}\right.$ and $\left.\mathrm{HCl}\right)$ as the electron donors.

\section{Results and discussion}

\subsection{Structural and electronic properties of $I_{3}$}

It is well known that $\mathrm{I}_{2}$ can react with $\mathrm{I}^{-}$easily in a solution, forming the strong halogen bonding complex $\mathrm{I}_{3}{ }^{-}$. As shown in Fig. 2a, we scanned the energy of $\mathrm{I}_{3}{ }^{-}$by changing the distance of $\mathrm{I}(1) \cdots \mathrm{I}(2)$ and $\mathrm{I}(2) \cdots \mathrm{I}(3)$ from $2.4 \AA$ to $6.0 \AA$. It is clear that the most stable structure is a linear molecule with two equal $\mathrm{I} \cdots \mathrm{I}$ length of $2.92 \AA$ (structure I). The black dash line can be seen as the dissociation pathway of $\mathrm{I}_{3}{ }^{-}$to $\mathrm{I}_{2} \cdots \mathrm{I}^{-}$, and we chose structures II and III with the distance of I(1) $\cdots \mathrm{I}(2)$ of 4.00 and $6.00 \AA$, respectively, to investigate the changes in the chemical bonding. Fig. $2 \mathrm{~b}$ gives the $3 \mathrm{c}-4 \mathrm{e}$ chemical bonding patterns of structures I, II and III by the AdNDP method.

For structure I, there are two symmetric 3c-2e bonds with idealized occupation numbers $2.00|e|$, corresponding to bonding and non-bonding bonds composed of three $5 \mathrm{p}$ orbitals of I atoms. When the length of $\mathrm{I}(1) \cdots \mathrm{I}(2)$ is fixed at $4.00 \AA$, the $\mathrm{I}(2) \cdots \mathrm{I}(3)$ distance is shortened to $2.73 \AA$ (structure II). Different from the symmetric $3 \mathrm{c}-2 \mathrm{e}$ bonds for structure $\mathrm{I}$, more electrons concentrate on $\mathrm{I}(1)$ and $\mathrm{I}(2)$ in the bonding orbital, while more electrons focus on $\mathrm{I}(2)$ and $\mathrm{I}(3)$ in the non-bonding orbital. Therefore, $\mathrm{I}_{2} \cdots \mathrm{I}^{-}$can also be explained by the $3 \mathrm{c}-4 \mathrm{e}$ bond model, just like $\mathrm{I}_{3}{ }^{-}$, and the difference is that the $3 \mathrm{c}-4 \mathrm{e}$ bond is polarized. Furthermore, when the $I(1) \cdots I(2)$ distance is further elongated to $6.00 \AA$ (structure III), the $3 \mathrm{c}-4 \mathrm{e}$ bonds is totally polarized, corresponding to one lone pair on $\mathrm{I}(1)$ and one $2 \mathrm{c}-2 \mathrm{e}$ $\sigma$ orbital between $\mathrm{I}(2)$ and I(3). Taken together, we can obtain that during dissociation, electrons of the $3 \mathrm{c}-2 \mathrm{e}$ bonding orbital in $\mathrm{I}_{3}{ }^{-}$undergoes a shift to $\mathrm{I}(1) \cdots \mathrm{I}(2)$ and finally focus on $\mathrm{I}(1)$, while that of 3c-2e non-bonding orbitals finally concentrate on the $\sigma$ bond between I(2) and I(3). Therefore, we can conclude that besides $\mathrm{I}_{3}{ }^{-}$, interactions in other products during dissociation should also be ascribed to multicenter bonds.

Traditionally, halogen bonding complexes should be explained as a charge transfer from the donor lone pair of $\mathrm{I}^{-}$to the $\sigma^{*}$ orbital of $\mathrm{I}_{2}$ or electrostatic attraction between $\mathrm{I}^{-}$and $\sigma$ hole of $\mathrm{I}_{2}$. For comparison, Fig. 2c gives the AdNDP bonding orbitals of structures I, II and III based on the $\mathrm{I}_{2}+\mathrm{I}^{-}$model (2c$2 \mathrm{e} / 1 \mathrm{c}-2 \mathrm{e}$ ). In structure III, $\mathrm{I}^{-}$is far enough with $\mathrm{I}_{2}$ molecule, so it is a typical compound with a weak halogen bond. In this situation, the $3 \mathrm{c}-4 \mathrm{e}$ model is very similar to the $2 \mathrm{c}-2 \mathrm{e} / 1 \mathrm{c}-2 \mathrm{e}$ model in the bonding picture. In structure II, the halogen bond $[\mathrm{I}(1) \cdots$ $\mathrm{I}(2)$ ] is strengthened, and the non-Lewis component of the bonding orbitals according to the $\mathrm{I}_{2}+\mathrm{I}^{-}$model increases, where the $\mathrm{ON}$ value of $1 \mathrm{c}-2 \mathrm{e}$ orbital decreases to $1.84|e|$. The lower ON value suggests that electron transfer from $\mathrm{I}^{-}$to $\mathrm{I}_{2}$ should be considered. This phenomenon becomes more obvious for the equilibrium structure (I), the ON value of non-bonding orbital being quite small $(1.49|e|)$. Therefore, the polarized $3 \mathrm{c}-4 \mathrm{e}$ bond model is consistent with the traditional $2 \mathrm{c}-2 \mathrm{e} / 1 \mathrm{c}-2 \mathrm{e}$ model for the cases with a weak halogen bond (structure III), whereas it is

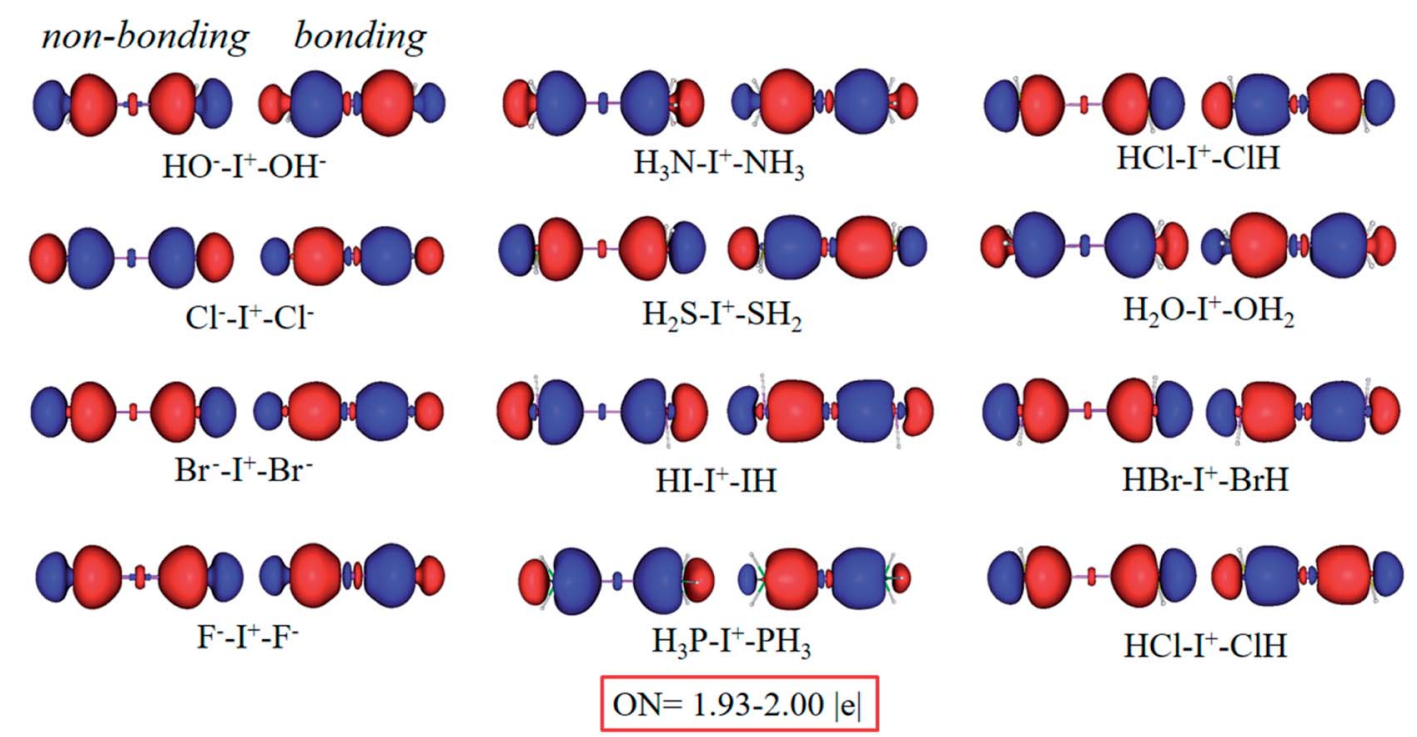

Fig. 6 Bonding (right) and non-bonding (left) $3 c-2 e$ orbitals of $L-I^{+}-L$ complexes by the AdNDP analysis. 


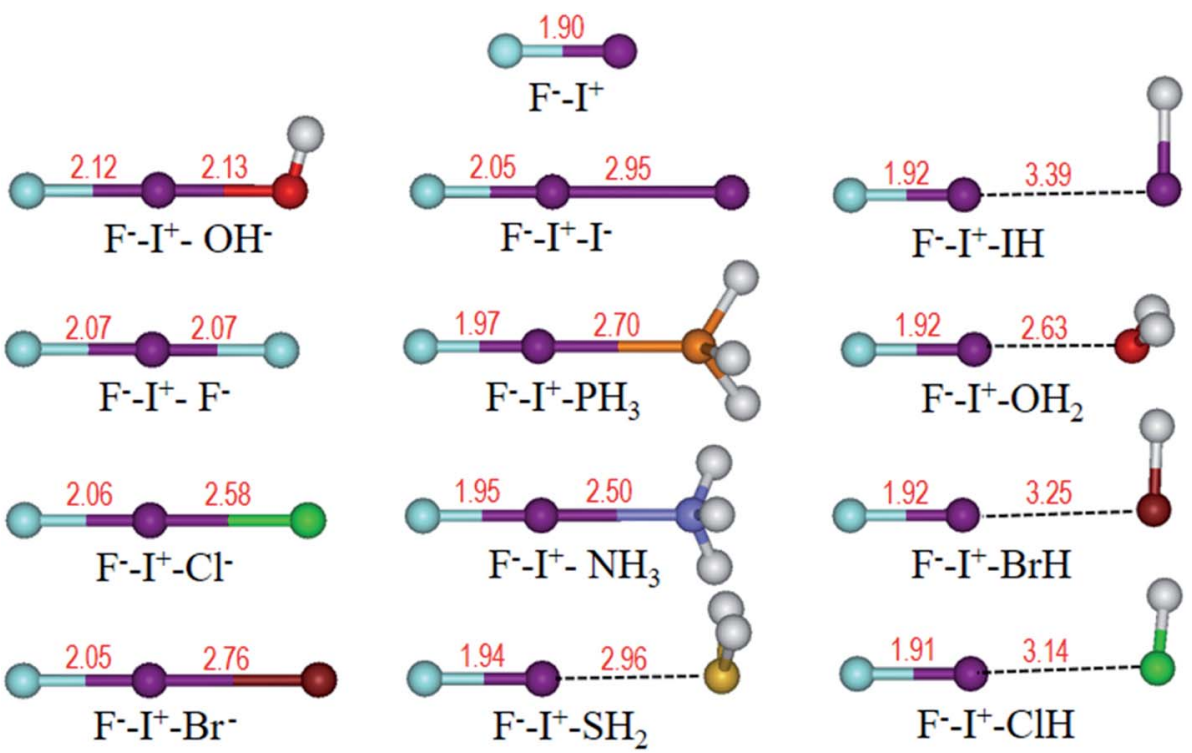

Fig. 7 Optimized structures of $\mathrm{F}^{-}-\mathrm{I}^{+}$and $\mathrm{F}^{-}-\mathrm{I}^{+}-\mathrm{L}\left(\mathrm{L}=\mathrm{OH}^{-}, \mathrm{F}^{-}, \mathrm{Cl}^{-}, \mathrm{Br}^{-}, \mathrm{I}^{-}, \mathrm{PH}_{3}, \mathrm{NH}_{3}, \mathrm{H}_{2} \mathrm{~S}, \mathrm{HI}, \mathrm{H}_{2} \mathrm{O}, \mathrm{HBr}\right.$ and $\left.\mathrm{HCl}\right)$ complexes. Bond length $(\AA \AA)$ is labelled in red.

more reasonable to describe the cases with a strong halogen bond (structures I and II).

To further confirm the essence of the multicenter bond discussed above, other properties corresponding to products obtained from the dissociation of $\mathrm{I}_{3}{ }^{-}$were studied, as shown in Fig. 3. The bond order (Fig. 3a) of $I(1) \cdots I(2)$ decreases with the increase in the $\mathrm{I}(1) \cdots \mathrm{I}(2)$ distance, and gradually approaches to zero. Moreover, those of $\mathrm{I}(2) \cdots \mathrm{I}(3)$ increase gradually and finally reach 1.5. Besides, the spike values of the NCI analysis (Fig. 3b) indicate that the interaction between $\mathrm{I}(2)$ and $\mathrm{I}(3)$ becomes stronger during dissociations with more negative values, and NBO charges (Fig. 3c) show that most charges finally concentrate on I(1). All the results are in good accordance with the AdNDP results discussed above, and suggest the same conclusion: interaction between $\mathrm{I}(1)$ and $\mathrm{I}(2)$ being weakened, whereas that between I(2) and I(3) being strengthened during dissociation, corresponding to the symmetric $3 \mathrm{c}-4 \mathrm{e}$ bond changing to a polarized $3 \mathrm{c}-4 \mathrm{e}$ one.

\subsection{Structural and electronic properties of $\mathrm{L}-\mathrm{I}^{+}-\mathrm{L}$}

$\mathrm{I}_{3}{ }^{-}$can be described by the Lewis theory model with the middle $\mathrm{I}^{+}$cation serving as the Lewis acid and two terminal $\mathrm{I}^{-}$anions acting as the Lewis base. Inspired by this, a series of electron donors $\mathrm{L}\left(\mathrm{L}=\mathrm{OH}^{-}, \mathrm{F}^{-}, \mathrm{Cl}^{-}, \mathrm{Br}^{-}, \mathrm{I}^{-}, \mathrm{PH}_{3}, \mathrm{NH}_{3}, \mathrm{H}_{2} \mathrm{~S}, \mathrm{HI}, \mathrm{H}_{2} \mathrm{O}\right.$, $\mathrm{HBr}$ and $\mathrm{HCl}$ ) were chosen to interact with $\mathrm{I}^{+}$to explore whether multicenter bonding can also be applied to other equivalent halogen bonding compounds $\left(\mathrm{L}-\mathrm{I}^{+}-\mathrm{L}\right)$. Binding energies of $\mathrm{I}^{+}$ with different bases were calculated (Table $2, E_{\mathrm{b}}=E\left(\mathrm{I}^{+}-\mathrm{L}\right)-$ $\left.E\left(\mathrm{I}^{+}\right)-E(\mathrm{~L})\right)$, spanning over a wide range, from -16.25 to $-252.40 \mathrm{kcal} \mathrm{mol}^{-1}$. Based on the binding energy, it is clear that

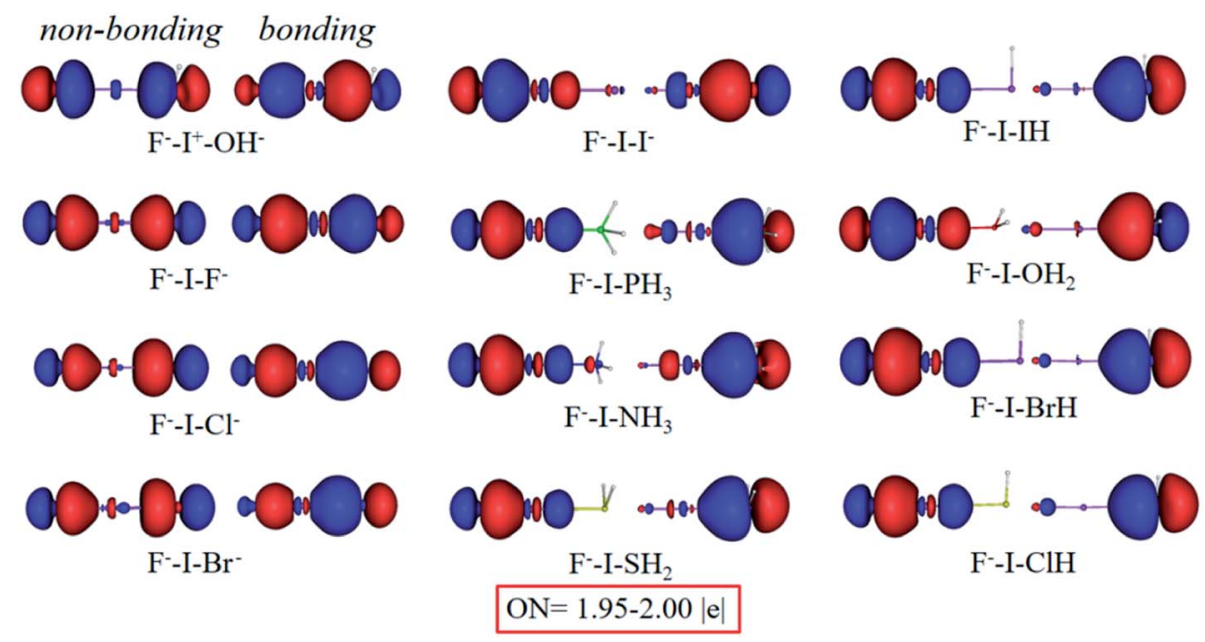

Fig. 8 Bonding (right) and non-bonding (left) $3 c-2 e$ orbitals of $\mathrm{F}^{-}-\mathrm{I}^{+}-\mathrm{L}$ complexes by the AdNDP analysis. 


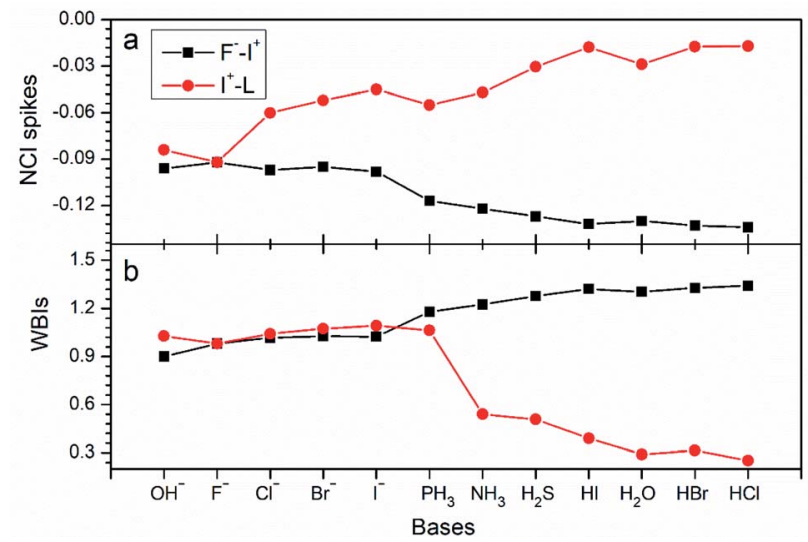

Fig. 9 Values of (a) $\mathrm{NCl}$ spikes and (b) WBIs of $\mathrm{F}^{-}-\mathrm{I}^{+}$and $\mathrm{I}^{+}-\mathrm{L}^{\text {in } \mathrm{F}^{-}-}$ $\mathrm{I}^{+}-\mathrm{L}$ complexes with different bases $\left(\mathrm{OH}^{-}, \mathrm{F}^{-}, \mathrm{Cl}^{-}, \mathrm{Br}^{-}, \mathrm{I}^{-}, \mathrm{PH}_{3}, \mathrm{NH}_{3}\right.$, $\mathrm{H}_{2} \mathrm{~S}, \mathrm{HI}, \mathrm{H}_{2} \mathrm{O}, \mathrm{HBr}$ and $\mathrm{HCl}$ ) as the electron donors.

the strength of the Lewis base decreases in the order: $\mathrm{OH}^{-}>\mathrm{F}^{-}$ $>\mathrm{Cl}^{-}>\mathrm{Br}^{-}>\mathrm{I}^{-}>\mathrm{PH}_{3}>\mathrm{NH}_{3}>\mathrm{H}_{2} \mathrm{~S}>\mathrm{HI}>\mathrm{H}_{2} \mathrm{O}>\mathrm{HBr}>\mathrm{HCl}$.

Optimized structures of $\mathrm{I}^{+}-\mathrm{L}$ and $\mathrm{L}-\mathrm{I}^{+}-\mathrm{L}$ are shown in Fig. 4. It can be observed that all the $\mathrm{L}-\mathrm{I}^{+}-\mathrm{L}$ angles are nearly linear with two equal $\mathrm{I}^{+} \cdots \mathrm{L}$ distances, which are obviously longer than those in $\mathrm{L}^{-} \mathrm{I}^{+}$monomers, similar to that in $\mathrm{I}_{3}{ }^{-}$. Besides, WBIs in Fig. 5 suggest that the values of bond order between $\mathrm{I}^{+}$and $\mathrm{L}$ in $\mathrm{L}-\mathrm{I}^{+}-\mathrm{L}$ complexes are less than those in the corresponding $\mathrm{I}^{+}-\mathrm{L}$ monomers, which is in accordance with the changes in the bond lengths.

Furthermore, it can be easily observed from the AdNDP analysis (Fig. 6) that all complexes can be well described by two symmetric bonding and non-bonding orbitals with reliable occupation numbers (1.93-2.00|e|), just like $\mathrm{I}_{3}{ }^{-}$. Therefore, as long as two forces around the central $\mathrm{I}^{+}$are the same, it corresponds to an equivalent $3 \mathrm{c}-4 \mathrm{e}$ bond interaction.

\subsection{Structural and electronic properties of $\mathbf{F}^{-}-\mathbf{I}^{+}-\mathbf{L}$}

Frequently, halogen bonding compounds do not own a perfect structural symmetry. Thus, we further extended our study to more general species. Electron donors on one side of $\mathrm{I}^{+}$was fixed to $\mathrm{F}^{-}$, and the other side was different bases, as shown in Table 2, forming halogen boding complexes of $\mathrm{F}^{-}-\mathrm{I}^{+}-\mathrm{L}(\mathrm{L}=$ $\mathrm{OH}^{-}, \mathrm{F}^{-}, \mathrm{Cl}^{-}, \mathrm{Br}^{-}, \mathrm{I}^{-}, \mathrm{PH}_{3}, \mathrm{NH}_{3}, \mathrm{H}_{2} \mathrm{~S}, \mathrm{HI}, \mathrm{H}_{2} \mathrm{O}, \mathrm{HBr}$ and $\mathrm{HCl}$ ). The optimized structures (Fig. 7) show that the angles of $\mathrm{F} \cdots \mathrm{I} \cdots \mathrm{L}$ approach to $180^{\circ}$, and $\mathrm{F} \cdots \mathrm{I}$ distances are all longer than that in the FI monomer of $1.90 \AA$ (Fig. 7) at the same theoretical level.

As expected, the chemical bonding analysis (Fig. 8) indicated that there are two $3 \mathrm{c}-2 \mathrm{e}$ orbitals for each species with idealized occupation numbers (1.95-2.00|e|). In case of $\mathrm{OH}^{-}, \mathrm{F}^{-}, \mathrm{Cl}^{-}$and $\mathrm{Br}^{-}$as electron donors, all bonding and non-bonding orbitals are evident and in good symmetry. When the electron donors change to $\mathrm{I}^{-}, \mathrm{PH}_{3}$ and $\mathrm{NH}_{3}$, it is clear that $3 \mathrm{c}-4 \mathrm{e}$ orbitals are polarized, just like those in $\mathrm{I}_{2} \cdots \mathrm{I}^{-}$, bonding orbitals being mainly focused on the $\mathrm{I}^{+}-\mathrm{L}$ segment, while non-bonding orbitals concentrating on the other terminals. In terms of the rest of the complexes, owing to their weak binding ability with $\mathrm{I}^{+}$, the polarization becomes clearer. Two $3 \mathrm{c}-2 \mathrm{e}$ orbitals of each are totally polarized to one $\sigma$ bond between $\mathrm{F}$ and I and one lone pair electrons at the other end. In addition, NCI spikes (Fig. 9a) are in good agreement with the AdNDP results. As the bases change from $\mathrm{OH}^{-}$to $\mathrm{HCl}$, interaction between $\mathrm{F}$ and I become stronger with more negative values, while those between I and $\mathrm{L}$ become weaker. WBIs in Fig. 9b further support the conclusion; when the binding ability of bases is strong enough $\left(\mathrm{OH}^{-}, \mathrm{F}^{-}\right.$, $\left.\mathrm{Cl}^{-}, \mathrm{Br}^{-}, \mathrm{I}^{-}\right)$, values of the bond order of $\mathrm{F}^{-}-\mathrm{I}^{+}$are close to those of $\mathrm{I}^{+}-\mathrm{L}$. However, there are big gaps for weak bases, and electrons mainly concentrate on $\mathrm{F}^{-}-\mathrm{I}^{+}$. Therefore, we can infer that the multicenter bond can be extended to rationalize more general halogen bonding compounds.

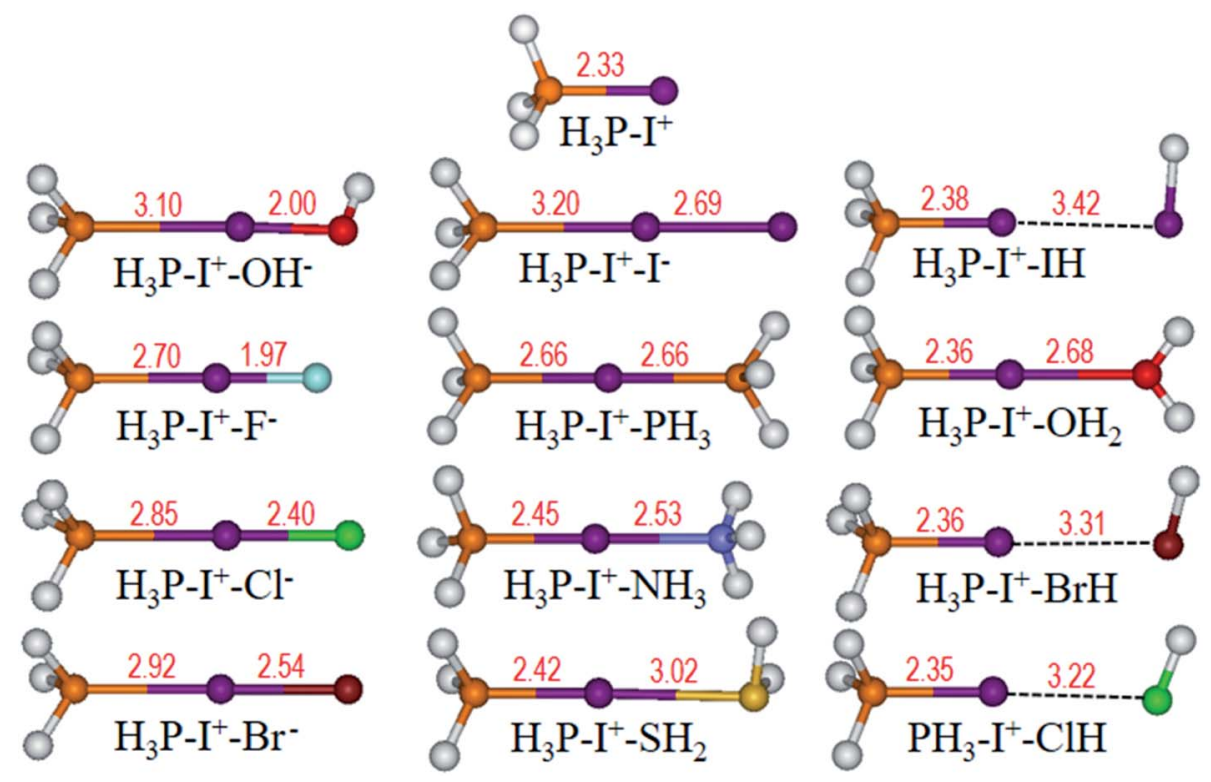

Fig. 10 Optimized structures of $\mathrm{H}_{3} \mathrm{P}-\mathrm{I}^{+}$and $\mathrm{H}_{3} \mathrm{P}-\mathrm{I}^{+}-\mathrm{L}\left(\mathrm{L}=\mathrm{OH}^{-}, \mathrm{F}^{-}, \mathrm{Cl}^{-}, \mathrm{Br}^{-}, \mathrm{I}^{-}, \mathrm{PH}_{3}, \mathrm{NH}_{3}, \mathrm{H}_{2} \mathrm{~S}, \mathrm{HI}, \mathrm{H} \mathrm{O}_{2} \mathrm{O} \mathrm{HBr}\right.$ and $\left.\mathrm{HCl}\right)$ complexes. Bond length $(\AA)$ is labelled in red. 


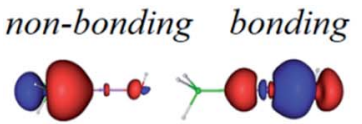

$\mathrm{H}_{3} \mathrm{P}-\mathrm{I}^{+}-\mathrm{OH}^{-}$

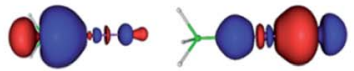

$\mathrm{H}_{3} \mathrm{P}-\mathrm{I}^{+}-\mathrm{F}^{-}$

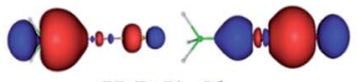

$\mathrm{H}_{3} \mathrm{P}_{-} \mathrm{I}^{+}-\mathrm{Cl}^{-}$

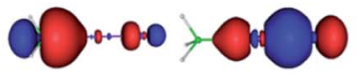

$\mathrm{H}_{3} \mathrm{P}^{-\mathrm{I}^{+}-\mathrm{Br}}$

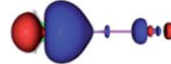

$\mathrm{H}_{3} \mathrm{P}-\mathrm{I}^{+}-\mathrm{I}^{-}$

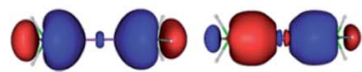

$\mathrm{H}_{3} \mathrm{P}-\mathrm{I}^{+}-\mathrm{PH}_{3}$

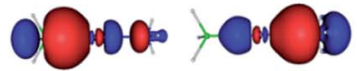

$\mathrm{H}_{3} \mathrm{P}-\mathrm{I}^{+}-\mathrm{NH}_{3}$

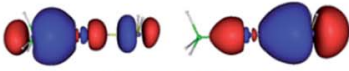

$\mathrm{H}_{3} \mathrm{P}-\mathrm{I}^{+}-\mathrm{SH}_{2}$

$O N=1.93-2.00|e|$

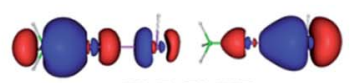

$\mathrm{H}_{3} \mathrm{P}-\mathrm{I}^{+}-\mathrm{IH}$

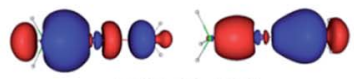

$\mathrm{H}_{3} \mathrm{P}-\mathrm{I}^{+}-\mathrm{OH}_{2}$

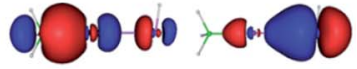

$\mathrm{H}_{3} \mathrm{P}-\mathrm{I}^{+}-\mathrm{BrH}$

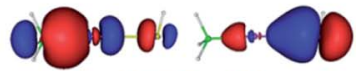

$\mathrm{H}_{3} \mathrm{P}-\mathrm{I}^{+}-\mathrm{ClH}$

Fig. 11 Bonding (right) and non-bonding (left) 3c-2e orbitals of $\mathrm{PH}_{3}-\mathrm{I}^{+}-\mathrm{L}$ complexes by the AdNDP analysis.

\subsection{Structural and electronic properties of $\mathrm{H}_{3} \mathrm{P}-\mathrm{I}^{+}-\mathrm{L}$}

Finally, we fixed the medium base $\mathrm{PH}_{3}$ to investigate the halogen bonding property with various bases: $\mathrm{H}_{3} \mathrm{P}-\mathrm{I}^{+}-\mathrm{L}(\mathrm{L}=$ $\mathrm{OH}^{-}, \mathrm{F}^{-}, \mathrm{Cl}^{-}, \mathrm{Br}^{-}, \mathrm{I}^{-}, \mathrm{PH}_{3}, \mathrm{NH}_{3}, \mathrm{H}_{2} \mathrm{~S}, \mathrm{HI}, \mathrm{H}_{2} \mathrm{O}, \mathrm{HBr}$ and $\mathrm{HCl}$ ). Similarly, the optimized structures (Fig. 10) show that two bases interact with $\mathrm{I}^{+}$at $180^{\circ}$ angles. Compared with the P-I bond length of $2.33 \AA$ in the $\mathrm{H}_{3} \mathrm{P}-\mathrm{I}^{+}$monomer (Fig. 10), P $\cdots$ I distances are elongated when bonding to other electron donors and vary within a wide range from 2.35 to $3.20 \AA$ A.

Chemical bonding analysis with two $3 \mathrm{c}-2 \mathrm{e}$ orbitals for each are depicted in Fig. 11. Differently from the $\mathrm{F}^{-}-\mathrm{I}^{+}-\mathrm{L}$ complexes in Fig. 8, because $\mathrm{OH}^{-}, \mathrm{F}^{-}, \mathrm{Cl}^{-}$and $\mathrm{I}^{-}$are stronger bases than $\mathrm{PH}_{3}$, orbitals of these species are directly polarized, and more $\sigma$ character focus on the $\mathrm{I}^{+}-\mathrm{L}$ segments in the bonding orbitals, whereas the non-bonding orbitals serve as the lone pair electrons. Symmetric bonding and non-bonding orbitals emerge when $\mathrm{I}^{+}$interacts with two equal $\mathrm{PH}_{3}$ groups. When the bases are further weakened $\left(\mathrm{NH}_{3}, \mathrm{SH}_{2}, \mathrm{HI}, \mathrm{H}_{2} \mathrm{O}, \mathrm{HBr}\right.$ and $\left.\mathrm{HCl}\right)$, the

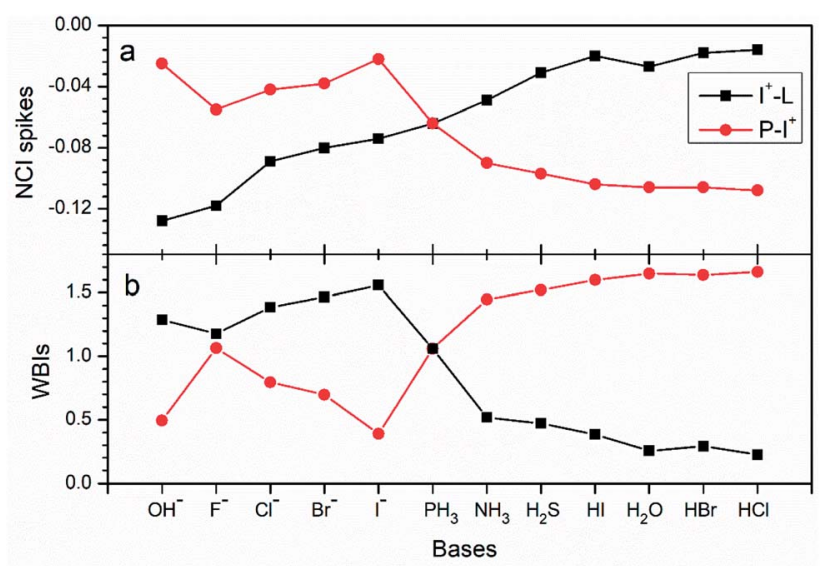

Fig. 12 Values of (a) $\mathrm{NCl}$ spikes and (b) WBIs of $\mathrm{I}^{+}-\mathrm{L}$ and $\mathrm{P}_{-} \mathrm{I}^{+}$in $\mathrm{H}_{3} \mathrm{P}-$ $\mathrm{I}^{+}-\mathrm{L}$ complexes with different bases $\left(\mathrm{OH}^{-}, \mathrm{F}^{-}, \mathrm{Cl}^{-}, \mathrm{Br}^{-}, \mathrm{I}^{-}, \mathrm{PH}_{3}, \mathrm{NH}_{3}\right.$, $\mathrm{H}_{2} \mathrm{~S}, \mathrm{HI}, \mathrm{H}_{2} \mathrm{O}, \mathrm{HBr}$ and $\mathrm{HCl}$ ) as the electron donors. orbitals are polarized again. Differently from the first four strong groups $\left(\mathrm{OH}^{-}, \mathrm{F}^{-}, \mathrm{Cl}^{-}\right.$and $\left.\mathrm{I}^{-}\right)$as bases, more electrons concentrating on the $\mathrm{H}_{3} \mathrm{P}-\mathrm{I}^{+}$segments and finally act as $2 \mathrm{c}-2 \mathrm{e} \sigma$ bonds in the $3 \mathrm{c}-2 \mathrm{e}$ non-bonding orbitals. Moreover, in the $3 \mathrm{c}-2 \mathrm{e}$ bonding orbitals, more electrons focus on the $\mathrm{I}^{+}-\mathrm{L}$ parts and finally serve as the lone pair electrons. NCI and bond order analysis in Fig. 12 show that stronger interactions (more negative values in spikes and more positive values in WBIs) located on the $\mathrm{I}^{+}-\mathrm{L}$ segments in case of $\mathrm{OH}-, \mathrm{F}-, \mathrm{Cl}-$ and $\mathrm{I}-$, but when it comes to $\mathrm{NH}_{3}, \mathrm{SH}_{2}, \mathrm{HI}, \mathrm{H}_{2} \mathrm{O}, \mathrm{HBr}$ and $\mathrm{HCl}$, stronger interactions transfer to the $\mathrm{P}-\mathrm{I}^{+}$segments, following the same trend with the AdNDP methods. Therefore, the multicenter bond is further illustrated to be capable to be applied to more halogen bonding compounds.

\section{Conclusions}

A series of complexes formed by $\mathrm{I}^{+}$and representative electron donors as well as $\mathrm{I}_{3}{ }^{-}$have been examined theoretically to gain a deeper insight into the nature of halogen bonding. It can be easily observed that during the dissociation of $\mathrm{I}_{3}{ }^{-}$, equivalent $3 \mathrm{c}-4 \mathrm{e}$ bonds gradually changed to polarized orbitals, and finally served as one $2 \mathrm{c}-2 \mathrm{e} \sigma$ bond and one lone pair of electrons. We concluded that both $\mathrm{I}_{3}{ }^{-}$and $\mathrm{I}_{2} \cdots \mathrm{I}^{-}$can be described by a multicenter bond, and the traditional charge transfer or $\sigma$ hole model should be incorporated into a polarized $3 \mathrm{c}-4 \mathrm{e}$ bond. In addition, the other I-containing complexes can also be explained by the $3 \mathrm{c}-4 \mathrm{e}$ bond, all of them having two $3 \mathrm{c}-2 \mathrm{e}$ orbitals with reliable ON values. When the forces of two bases around $\mathrm{I}^{+}$are the same, it possesses clear bonding and nonbonding orbitals, corresponding to the equivalent $3 \mathrm{c}-4 \mathrm{e}$ bond. When the forces are different, it is a polarized $3 c-4 e$ bond. Thus, our study revisits the covalent nature of halogen bonding and comes to the conclusion that not only the well-known $\mathrm{I}_{3}{ }^{-}$, but also all halogen bonding compounds are dominant by a multicenter bond, existing equivalent and polarized $3 \mathrm{c}-4 \mathrm{e}$ bonds, 
respectively. We hope that it can be applied to explain more halogen bonding complexes.

\section{Conflicts of interest}

The authors declare no competing financial interests.

\section{Acknowledgements}

This work was supported by the National Natural Science Foundation of China (Grant No. 21873001) and by the Foundation of Distinguished Young Scientists of Anhui Province.

\section{References}

1 C. B. Aakeroy, M. Fasulo, N. Schultheiss, J. Desper and C. Moore, J. Am. Chem. Soc., 2007, 129, 13772.

2 G. Cavallo, P. Metrangolo, R. Milani, T. Pilati, A. Priimagi, G. Resnati and G. Terraneo, Chem. Rev., 2016, 116, 24782601.

3 L. C. Gilday, S. W. Robinson, T. A. Barendt, M. J. Langton, B. R. Mullaney and P. D. Beer, Chem. Rev., 2015, 115, 71187195.

4 P. Metrangolo, F. Meyer, T. Pilati, G. Resnati and G. Terraneo, Angew. Chem., Int. Ed., 2008, 47, 6114-6127.

5 P. Metrangolo, H. Neukirch, T. Pilati and G. Resnati, Acc. Chem. Res., 2005, 38, 386-395.

6 P. Von R. Schleyer and R. West, J. Am. Chem. Soc., 1959, 81, 3164-3165.

7 M. Colin, Ann. Chim., 1814, 91, 252-272.

8 F. Guthrie, J. Chem. Soc., 1863, 16, 239-244.

9 I. Remsen and J. Norris, Am. Chem. J., 1896, 18, 90-95.

10 J. M. Guevara Vela, D. Ochoa Resendiz, M. A. Costales Castro, R. Hernández Lamoneda and Á. Martín Pendás, ChemPhysChem, 2018, 19, 2512-2517.

11 D. M. Ivanov, A. S. Novikov, I. V. Ananyev, Y. V. Kirina and V. Y. Kukushkin, Chem. Commun., 2016, 52, 5565-5568.

12 A. C. Legon, Phys. Chem. Chem. Phys., 2010, 12, 7736-7747.

13 C. Z. Liu, S. Koppireddi, H. Wang, D. W. Zhang and Z. T. Li, Angew. Chem., Int. Ed., 2019, 58, 226-230.

14 M. Niyas, R. Ramakrishnan, V. Vijay, E. Sebastian and M. Hariharan, J. Am. Chem. Soc., 2019, 141, 4536-4540.

15 P. Politzer and J. S. Murray, ChemPhysChem, 2013, 14, 278294.

16 P. Politzer, J. S. Murray and T. Clark, Phys. Chem. Chem. Phys., 2013, 15, 11178-11189.

17 S. Scheiner, CrystEngComm, 2013, 15, 3119-3124.

18 S. Scheiner, CrystEngComm, 2019, 21, 2875-2883.

19 A. Vanderkooy, A. K. Gupta, T. Földes, S. Lindblad, A. Orthaber, I. Pápai and M. Erdélyi, Angew. Chem., Int. Ed. Engl., 2019, 131, 9110-9114.

20 A. R. Voth, P. Khuu, K. Oishi and P. S. Ho, Nat. Chem., 2009, 1,74 .

21 L. Meazza, J. A. Foster, K. Fucke, P. Metrangolo, G. Resnati and J. W. Steed, Nat. Chem., 2013, 5, 42-47.
22 T. Caronna, R. Liantonio, T. A. Logothetis, P. Metrangolo, T. Pilati and G. Resnati, J. Am. Chem. Soc., 2004, 126, 45004501.

23 A. Farina, S. V. Meille, M. T. Messina, P. Metrangolo, G. Resnati and G. Vecchio, Angew. Chem., Int. Ed., 1999, 38, 2433-2436.

24 G. Bergamaschi, L. Lascialfari, A. Pizzi, M. I. M. Espinoza, N. Demitri, A. Milani, A. Gori and P. Metrangolo, Chem. Commun., 2018, 54, 10718-10721.

25 B. Hawthorne, H. Fan-Hagenstein, E. Wood, J. Smith and T. Hanks, Int. J. Spectrosc., 2013, 2013, 216518-216527.

26 J. Xu, X. Liu, T. Lin, J. Huang and C. He, Macromolecules, 2005, 38, 3554-3557.

27 T. M. Beale, M. G. Chudzinski, M. G. Sarwar and M. S. Taylor, Chem. Soc. Rev., 2013, 42, 1667-1680.

28 N. Cheetham and A. Pullin, Chem. Commun., 1967, 233-234. 29 R. Wilcken, M. O. Zimmermann, A. Lange, A. C. Joerger and F. M. Boeckler, J. Med. Chem., 2013, 56, 1363-1388.

30 Y. Lu, Y. Wang and W. Zhu, Phys. Chem. Chem. Phys., 2010, 12, 4543-4551.

31 H. Matter, M. Nazaré, S. Güssregen, D. W. Will, H. Schreuder, A. Bauer, M. Urmann, K. Ritter, M. Wagner and V. Wehner, Angew. Chem., Int. Ed., 2009, 48, 2911-2916. 32 T. Xia, D. Li and L. Cheng, Chem. Phys., 2020, 539, 110978. 33 R. S. Mulliken, J. Am. Chem. Soc., 1950, 72, 600-608.

34 H. A. Bent, Chem. Rev., 1968, 68, 587-648.

35 D. Bulfield and S. M. Huber, Chem.-Eur. J., 2016, 22, 1443414450.

36 O. Hassel, Science, 1970, 170, 497-502.

37 S. M. Huber, J. D. Scanlon, E. Jimenez-Izal, J. M. Ugalde and I. Infante, Phys. Chem. Chem. Phys., 2013, 15, 10350-10357.

38 A. E. Reed, F. Weinhold, R. Weiss and J. Macheleid, J. Phys. Chem., 1985, 89, 2688-2694.

39 S. W. Robinson, C. L. Mustoe, N. G. White, A. Brown, A. L. Thompson, P. Kennepohl and P. D. Beer, J. Am. Chem. Soc., 2015, 137, 499-507.

40 C. Wang, D. Danovich, Y. Mo and S. Shaik, J. Chem. Theory Comput., 2014, 10, 3726-3737.

41 L. P. Wolters and F. M. Bickelhaupt, ChemistryOpen, 2012, 1, 96-105.

42 P. Politzer, P. Lane, M. C. Concha, Y. Ma and J. S. Murray, J. Mol. Model., 2007, 13, 305-311.

43 P. Politzer, J. S. Murray and M. C. Concha, J. Mol. Model., 2007, 13, 643-650.

44 Y.-X. Lu, J.-W. Zou, Y.-H. Wang, Y.-J. Jiang and Q.-S. Yu, J. Phys. Chem. A, 2007, 111, 10781-10788.

45 K. E. Riley, J. S. Murray, P. Politzer, M. C. Concha and P. Hobza, J. Chem. Theory Comput., 2009, 5, 155-163.

46 S. M. Huber, E. Jimenez-Izal, J. M. Ugalde and I. Infante, Chem. Commun., 2012, 48, 7708-7710.

47 K. E. Riley and P. Hobza, Phys. Chem. Chem. Phys., 2013, 15, 17742-17751.

48 J. Thirman, E. Engelage, S. M. Huber and M. Head-Gordon, Phys. Chem. Chem. Phys., 2018, 20, 905-915.

49 B. Pinter, N. Nagels, W. A. Herrebout and F. De Proft, Chem.Eur. J., 2013, 19, 519-530. 
50 L. J. Prins, D. N. Reinhoudt and P. Timmerman, Angew. Chem., Int. Ed., 2001, 40, 2382-2426.

51 T. Steiner, Angew. Chem., Int. Ed., 2002, 41, 48-76.

52 B. Chen, I. Ivanov, M. L. Klein and M. Parrinello, Phys. Rev. Lett., 2003, 91, 215503.

53 C. Laurence and M. Berthelot, Perspect. Drug Discov. Des., 2000, 18, 39-60.

54 C. F. Matta, J. Hernández-Trujillo, T. H. Tang and R. F. Bader, Chem.-Eur. J., 2003, 9, 1940-1951.

55 E. Corradi, S. V. Meille, M. T. Messina, P. Metrangolo and G. Resnati, Angew. Chem., Int. Ed., 2000, 39, 1782-1786.

56 G. A. Landrum, N. Goldberg and R. Hoffmann, J. Chem. Soc., Dalton Trans., 1997, 3605-3613.

57 M. L. Green and G. Parkin, Dalton Trans., 2016, 45, 1878418795.

58 G. C. Pimentel, J. Chem. Phys., 1951, 19, 446-448.

59 K. Sonnenberg, L. Mann, F. A. Redeker, B. Schmidt and S. Riedel, Angew. Chem., Int. Ed., 2020, 59, 5464-5493.

60 A. Y. Rogachev and R. Hoffmann, Inorg. Chem., 2013, 52, 7161-7171.

61 S. Shaik, New J. Chem., 2007, 31, 2015-2028.

62 B. Dereka, Q. Yu, N. H. C. Lewis, W. B. Carpenter, J. M. Bowman and A. Tokmakoff, Science, 2021, 371, 160164 .
63 Y. Zhao and D. G. Truhlar, Acc. Chem. Res., 2008, 41, 157-167. 64 K. P. Huber and G. Herzberg, Constants of Diatomic Molecules, Van Nostrand Reinhold, New York, 1979.

65 A. Rosa, A. W. Ehlers, E. J. Baerends, J. G. Snijders and G. t. Velde, J. Phys. Chem., 1996, 100, 5690-5696.

66 E. R. Johnson, S. Keinan, P. Mori-Sánchez, J. ContrerasGarcía, A. J. Cohen and W. Yang, J. Am. Chem. Soc., 2010, 132, 6498-6506.

67 D. Y. Zubarev and A. I. Boldyrev, Phys. Chem. Chem. Phys., 2008, 10, 5207-5217.

68 A. E. Reed and F. Weinhold, J. Chem. Phys., 1983, 78, 40664073.

69 F. Weinhold, J. Comput. Chem., 2012, 33, 2363-2379.

70 M. Frisch, G. Trucks, H. Schlegel, G. Scuseria, M. Robb, J. Cheeseman, G. Scalmani, V. Barone, G. Petersson and H. Nakatsuji, Gaussian, Inc., Wallingford CT: 2016.

71 L. K. Harper, A. L. Shoaf and C. A. Bayse, ChemPhysChem, 2015, 16, 3886-3892.

72 T. Lu and F. Chen, J. Comput. Chem., 2012, 33, 580-592.

73 U. Varetto, MOLEKEL 5.4, Swiss National Supercomputing Centre, Manno, Switzerland, 2009. 